\title{
State of penicillin-binding proteins and requirements for their bactericidal interaction with $\beta$-lactam antibiotics in Serratia marcescens highly resistant to extended-spectrum $\beta$-lactams
}

\author{
Anna-Greta Gunkel, Ulrike Hechler $†$ and Hans H. Martin* \\ Institut für Mikrobiologie, Technische Hochschule Darmstadt, Schnittspahnstrasse 9, D-6100 Darmstadt, \\ Federal Republic of Germany
}

(Received 18 September 1990; accepted 6 October 1990)

\begin{abstract}
The quantities of penicillin-binding proteins (PBPs), and sensitivity to extended-spectrum $\beta$-lactams, were measured in isogenic strains of Serratia marcescens with high (HR) and low (LR) resistance to extended-spectrum $\beta$-lactam antibiotics and with constitutively overproduced chromosomal $\beta$-lactamase in the periplasm. The binding of structurally different $\beta$-lactams to PBPs in growing resistant bacteria was determined quantitatively. In $S$. marcescens HR, the amounts of PBPs 3 and 6 were, respectively, 1.5 and 2 times those in strain LR and in sensitive reference strains. Sensitivities of the essential PBPs in S. marcescens LR and HR to the tested $\beta$-lactams were identical. Only a single target, PBP 3, was highly sensitive to cefotaxime, ceftazidime and aztreonam. In contrast, three PBPs (2, 1A and 3) were highly sensitive to imipenem. In growing $S$. marcescens $H R$ and LR, all antibiotics, even at fractions of their minimal growth inhibitory concentrations (MICs), bound extensively to those PBPs which were highly sensitive to them. Thus, overproduced $\beta$-lactamase did not prevent PBP- $\beta$-lactam interaction. Only at or above their (high) MICs did cefotaxime, ceftazidime and aztreonam bind to multiple targets. Growth inhibition of the otherwise highly resistant $S$. marcescens $H R$ at the lower MIC of imipenem was correlated with the binding of this antibiotic to multiple, highly sensitive targets in the bacteria. Killing of the bacteria by inactivation of multiple targets was suggested. This assumption was supported by the synergistic killing of $\mathrm{HR}$ bacteria by combinations of the PBP-2-specific mecillinam with PBP-3-specific $\beta$-lactams.
\end{abstract}

\section{Introduction}

In various opportunistic pathogens among the Gramnegative bacteria, high resistance to $\beta$-lactam antibiotics as well as to the newer extended-spectrum compounds with increased stability to $\beta$-lactamases is encountered. This has been found to be related to the limitation of antibiotic penetration by the outer membrane barrier and the degradation of the $\beta$-lactams by overproduced, chromosomally encoded $\beta$-lactamase in the bacterial periplasm ( $\mathrm{Vu} \&$ Nikaido, 1985; Bush et al., 1985; Marchou et al., 1987; Nikaido \& Normark, 1987; Frère, 1989; Hechler et al., 1989; Nikaido, 1989). The

$\dagger$ Present address: Schering AG, D-1000 Berlin 65, FRG.

Abbreviations: HR, high resistance; LR, low resistance; PBP, penicillin-binding protein; MIC, minimal growth-inhibitory concentration; $\mathrm{EC}_{50}$, concentration of $\beta$-lactam reducing the binding of $\left[{ }^{3} \mathrm{H}\right]-$ benzylpenicillin to PBP by $50 \% ; \mathrm{I}_{\mathrm{pl}}$, lethal periplasmic concentration of antibiotic.

This paper is dedicated to Professor Otto Kandler on the occasion of his 70 th birthday. combined functions of both resistance factors are thought to block the access of the antibiotics to their targets, the essential penicillin-binding proteins (PBPs), on the bacterial cytoplasmic membrane.

In a previous study we demonstrated the validity of this concept by comparison of sensitive and $\beta$-lactamresistant strains of Serratia marcescens (Hechler et al., 1989). Mathematical models of the interaction of penetrating antibiotics with the permeability barrier and periplasmic $\beta$-lactamase (Frère, 1989; Frère et al., 1989) were used to determine the contribution of the two resistance factors to the high and low resistance to extended-spectrum $\beta$-lactam antibiotics in the isogenic $\beta$-lactamase-overproducing strains $S$. marcescens $921 / 79$ HR and LR. For some representative newer antibiotics, the action of $\beta$-lactamase alone accounted for the lower resistance of $S$. marcescens LR. For instance, the $\beta$-lactamase degraded cefotaxime, ceftazidime and aztreonam to concentrations below the required lethal periplasmic concentration $\left(I_{p l}\right.$; Frère, 1989) when these $\beta$-lactams were applied at external concentrations below 
their minimal growth inhibitory concentrations (MICs) of 32,1 and $8 \mu \mathrm{g} \mathrm{ml}^{-1}$, respectively. The antibiotics could then be assumed to penetrate at the same rate into cells of the LR strain and of sensitive reference strains of $S$. marcescens.

For the highly resistant $S$. marcescens $\mathrm{HR}$, with MICs of 1024,64 and $128 \mu \mathrm{g} \mathrm{ml}^{-1}$ for the antibiotics, the models revealed the requirement for a further resistance factor in addition to $\beta$-lactamase. Decreased outer membrane penetrability was tentatively assumed. However, increased amounts or decreased sensitivity of essential PBP targets were also possible causes of the high resistance.

It is not known which target(s) or what percentage of target molecules are inactivated in the resistant bacteria at the $\mathrm{I}_{\mathrm{pl}}$ and respective MIC of a given $\beta$-lactam.

In the present study, we determined the quantities of PBPs in sensitive and resistant strains of $S$. marcescens. Sensitivities of PBPs to extended-spectrum $\beta$-lactams in the differentially resistant $S$. marcescens $\mathrm{HR}$ and LR were compared. Binding of $\beta$-lactams to PBPs in growing cells of $S$. marcescens $\mathrm{HR}$ and LR was measured in order to assess the degree of inactivation of PBPs required for bactericidal action and to characterize the ability of the individual antibiotics to accomplish this task.

\section{Methods}

Bacteria. The resistant strains Serratia marcescens $921 / 79$ LR and HR, their different states of resistance, the MICs of extended-spectrum $\beta$-lactam antibiotics for these bacteria, and their constitutive overproduction of chromosomally encoded $\beta$-lactamase have been described (Hechler et al., 1989). The $\beta$-lactam-sensitive reference strains of $S$. marcescens were the type strain CCM 303 and clinical strains HIM 307-2, HIM 337-5 and HIM 697-6 (Professor Dr W. Mannheim, Med. Zentrum für Hygiene, Universität Marburg/Lahn, FRG).

Susceptibility tests. Determinations of MICs by standard macro broth dilution assay and checkerboard tests for the detection of antibacterial synergism of combinations of $\beta$-lactam antibiotics (Krogstadt \& Moellering, 1980) were performed in Mueller-Hinton broth.

Measurements of bactericidal kinetics were carried out in $20 \mathrm{ml} \mathrm{LB}$ broth (Miller, 1972) at $37^{\circ} \mathrm{C}$ with slow agitation at 90 r.p.m. on a rotary shaker, in order to avoid mechanical damage of the cells. Initial inocula were $10^{5}-10^{6}$ bacteria $\mathrm{ml}^{-1}$. The media were supplemented with individual $\beta$-lactam antibiotics or combinations thereof immediately before inoculation. Surviving bacteria were counted as c.f.u. on LBagar.

$\beta$-Lactamase. Assays of $\beta$-lactamase activity were performed as described previously (Hechler et al., 1989).

Assays of PBPs. PBPs in cell envelopes of $S$. marcescens were determined quantitatively by a modification of the technique of Spratt (1977). Isolated cell envelopes were prepared by sonication of bacteria harvested at an $\mathrm{OD}_{578}$ of 0.8 from cultures in $250 \mathrm{ml}$ Penassay broth (Difco) in 1 litre conical flasks incubated at $37^{\circ} \mathrm{C}$ on a rotary shaker at 180 r.p.m. The envelopes were freed from adherent $\beta$-lactamase, as far as possible, by repeated washings in $0.05 \mathrm{M}$-sodium phosphate buffer,
$\mathrm{pH} 7 \cdot 0$. Suspensions of envelopes in phosphate buffer containing $25 \mathrm{mg}$ protein $\mathrm{ml}^{-1}$ were stored at $-80^{\circ} \mathrm{C}$. For radioactive labelling of PBPs, envelope samples $(650 \mu \mathrm{g}$ protein) were mixed rapidly and simultaneously with cloxacillin at $1 \mu \mathrm{M}$ final concentration, to inactivate envelope-bound $\beta$-lactamase, and with $5 \mathrm{nmol}(10 \mu \mathrm{Ci}, 370 \mathrm{kBq})\left[{ }^{3} \mathrm{H}\right]-$ benzylpenicillin (Amersham Buchler, Braunschweig, FRG) with a specific activity of $74 \mathrm{GBq} \mathrm{mmol}^{-1}$ in a total volume of $55 \mu \mathrm{l} 0.05 \mathrm{M}$ sodium phosphate buffer, $\mathrm{pH} 7 \cdot 0$. After incubation for $20 \mathrm{~min}$ at $30^{\circ} \mathrm{C}$, the binding of labelled penicillin to the PBPs was stopped by the addition of unlabelled penicillin at a final concentration of $6 \mathrm{~mm}$. The following steps, solubilization of labelled PBPs by Sarkosyl, separation of PBPs by SDS-PAGE and detection of the PBPs on gels by fluorography, were carried out according to published procedures (Spratt, 1977). For SDS-PAGE, samples containing 50-200 $\mu \mathrm{g}$ protein were applied to lanes of $12 \mathrm{~mm}$ width on the stacking gel. Quantities of separated labelled PBPs were determined by locating them on the gels from their positions on the fluorograms. The PBP bands were cut out and the gel segments were allowed to swell by incubation with $0.2 \mathrm{ml}$ $\mathrm{H}_{2} \mathrm{O}$ in counting vials for $4 \mathrm{~h}$ at $50^{\circ} \mathrm{C}$. The radioactive material was then extracted by treatment with $1.5 \mathrm{ml}$ Protosol (NEN-DuPont) for $20 \mathrm{~h}$ at $37^{\circ} \mathrm{C}$ with agitation. After neutralization of the samples with $4 \mathrm{M}-\mathrm{HCl}$ and addition of $4 \mathrm{ml}$ Scintigel (C. Roth, $\mathrm{KG}$ ) the radioactivity was counted by scintillation spectrometry at $29 \%$ counting efficiency.

Binding of extended-spectrum B-lactams to PBPs in cell envelopes. Identical samples of envelopes as described above were incubated for $10 \mathrm{~min}$ at $30^{\circ} \mathrm{C}$ with a range of twofold increasing concentrations of unlabelled extended-spectrum $\beta$-lactams, in the presence of $1 \mu \mathrm{M}$ cloxacillin. Thereafter, PBPs to which the unlabelled $\beta$-lactams had not bound were labelled with $\left[{ }^{3} \mathrm{H}\right]$ benzylpenicillin, as described. Quantities of PBPs with bound extended-spectrum $\beta$-lactams were determined by subtracting the amounts of labelled PBPs in samples preincubated with the unlabelled $\beta$-lactams from those of control samples which were preincubated identically, except for the absence of extended-spectrum $\beta$-lactams. Saturation curves obtained from these values yielded concentrations $\left(\mathrm{EC}_{50}\right)$ of extended-spectrum $\beta$-lactams which prevented the binding of $\left[{ }^{3} \mathrm{H}\right]$ benzylpenicillin to $50 \%$ of the total amount of the PBPs (Spratt, 1977)

Binding of $\beta$-lactam antibiotics to PBPs in growing cells of $S$. marcescens 921/79 LR and HR. The bacteria were grown in shake cultures of $250 \mathrm{ml}$ Penassay medium (Difco) in 1 litre conical flasks at $37^{\circ} \mathrm{C}$. When the cultures had reached the exponential phase of growth, at an $\mathrm{OD}_{578}$ of $0.8, \beta$-lactam antibiotics at different concentrations were added and incubation was continued for $30 \mathrm{~min}$, during which period rotary agitation was reduced from 180 to 80 r.p.m., in order to avoid binding of $\beta$-lactams to PBPs in mechanically damaged cells. The cultures were then chilled in an ice bath. Low temperature was maintained during the subsequent isolation of cell envelopes, in order to avoid the decay of existing complexes of PBPs with $\beta$-lactams. The cells were harvested rapidly by centrifugation and cell sediments were freed of antibioticcontaining growth medium by washing them twice in sodium phosphate buffer by centrifugation. Isolated cell envelopes were prepared as described above. PBPs in the isolated envelopes which had not previously bound unlabelled $\beta$-lactam penetrating into the living bacteria were labelled with $\left[{ }^{3} \mathrm{H}\right]$ benzylpenicillin and counted. As controls, quantities of PBPs were determined in LR and HR strains taken through the same procedure, but without incubation of the cells with unlabelled $\beta$-lactams.

Antibiotics. $\beta$-Lactam antibiotics were kindly provided by the following companies: Merck, Sharp \& Dohme (imipenem); SquibbVon Heyden (aztreonam); Cascan (ceftazidime); Hoechst (cefotaxime); Eli Lilly (cephalexin); Rorer (mecillinam); Pfizer Central Research (6- $\beta$-iodopenicillanic acid); Beecham-Wülfing (cloxacillin). 

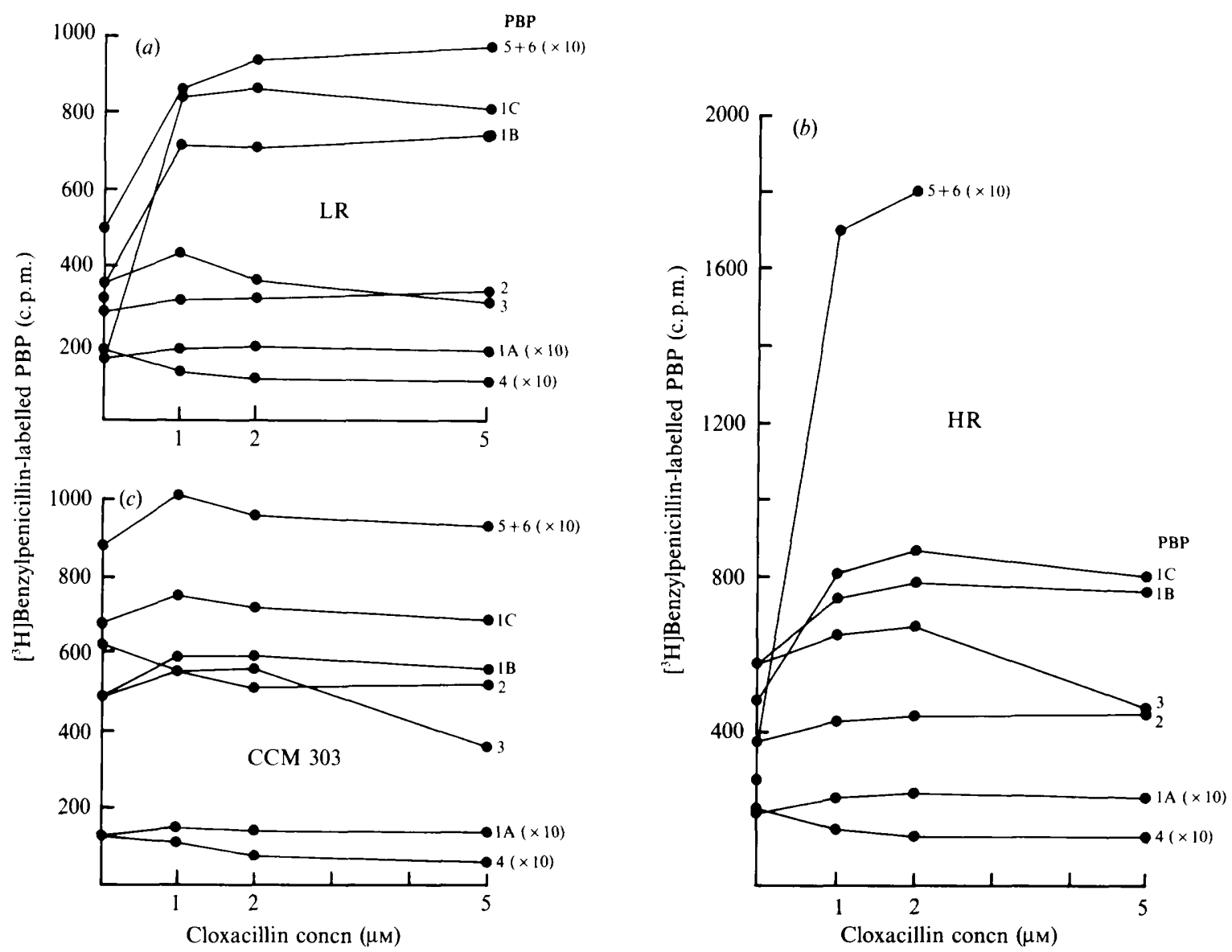

Fig. 1. Effect of the inactivation of envelope-bound $\beta$-lactamase by various cloxacillin concentrations on the covalent binding of $\left[{ }^{3} \mathrm{H}\right]-$ benzylpenicillin to PBPs in isolated envelopes of resistant $S$. marcescens, strains LR $(a)$ and HR $(b)$. As a control, competition of cloxacillin with $\left[{ }^{3} \mathrm{H}\right.$ ]benzylpenicillin for PBP binding was measured in envelopes of sensitive $S$. marcescens CCM 303 (c), which contained only a negligible amount of bound $\beta$-lactamase. For curves marked ' $(\times 10)$ ' the actual values measured were 10 times those plotted.

\section{Results and Discussion}

Quantitative determination of PBPs in the $\beta$-lactamaseoverproducing strains of $S$. marcescens

Envelopes prepared from the resistant, $\beta$-lactamaseoverproducing $S$. marcescens $921 / 79$ strains HR and LR contained firmly attached $\beta$-lactamase which could not be removed by repeated washing with buffer. Specific activities of $\beta$-lactamase in such envelopes were 57 and $30 \mathrm{mU}$ (mg protein $)^{-1}$, respectively, in comparison to 3 to $5 \mathrm{mU}$ (mg protein) ${ }^{-1}$ in envelopes of four sensitive reference strains. As a consequence, several PBPs, mainly $1 \mathrm{~B}, 1 \mathrm{C}, 5$ and 6 , were greatly underestimated by the standard PBP assay in envelopes of strains HR and $L R$, due to degradation by the envelope-bound $\beta$ lactamase of the $\left[{ }^{3} \mathrm{H}\right]$ benzylpenicillin used for PBP labelling.
Cloxacillin (Jack \& Richmond, 1970) and 6- $\beta$-iodopenicillanic acid (De Meester et al., 1986) were tested for their ability to inactivate the envelope-bound $\beta$-lactamase without simultaneous binding to PBPs. At concentrations required for complete inactivation of $\beta$-lactamase, 6 - $\beta$-iodopenicillanic acid also bound extensively to different PBPs. Cloxacillin inhibited the $S$. marcescens $\beta$ lactamase instantly and completely under PBP-assay conditions. The amounts of PBPs labelled by $\left[{ }^{3} \mathrm{H}\right]$ benzylpenicillin in the presence of different concentrations of cloxacillin were determined in envelopes of the resistant strains HR and LR and of the sensitive strain CCM 303. As shown in Fig. 1, inactivation of $\beta$-lactamase greatly increased the measurable quantities of PBPs $1 B, 1 C$ and $5 / 6$ in strains HR and LR, yielding a plateau at cloxacillin concentrations of $1-5 \mu \mathrm{M}$. In strain CCM 303 , on the other hand, cloxacillin at $1 \mu \mathrm{M}$ concentration bound to $10 \%$ of PBP 3 and $25 \%$ of PBP 4 , and to $40 \%$ 

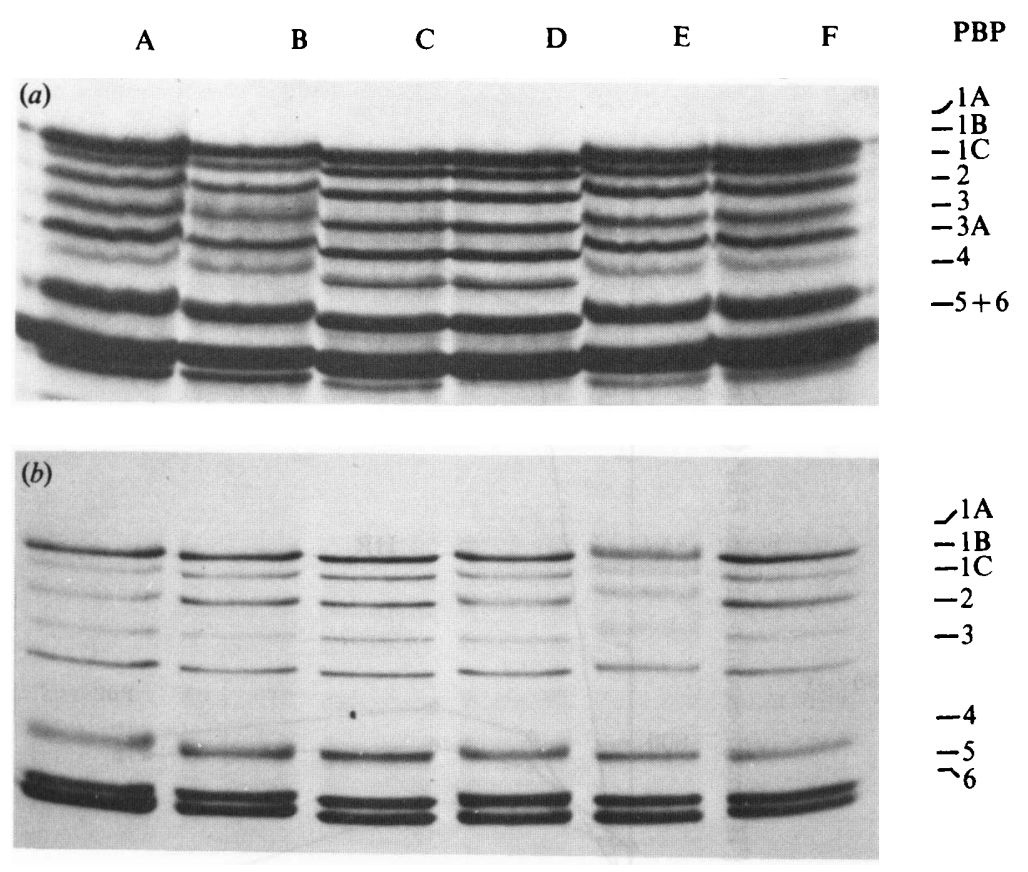

Fig. 2. SDS-PAGE of PBPs in $\beta$-lactam-resistant and -sensitive $S$. marcescens labelled with $\left[{ }^{3} \mathrm{H}\right]$ benzylpenicillin. Resistant strains: HR (lane A), LR (lane B). Sensitive strains: CCM 303 (lane C), HIM 307-2 (lane D), HIM 337-5 (lane E), HIM 697-6 (lane F). Samples contained $200 \mu \mathrm{g}(a)$ and $50 \mu \mathrm{g}(b)$ protein. and more of these PBPs at higher concentrations. Therefore, radioactive labelling of PBPs was generally performed in the presence of $1 \mu \mathrm{M}$-cloxacillin.

\section{Amounts of PBPs in resistant and sensitive strains of $S$. marcescens}

For quantitative comparison of PBPs in different strains of $S$. marcescens, equal amounts of isolated envelopes from identical numbers of bacteria were labelled with $\left[{ }^{3} \mathrm{H}\right]$ benzylpenicillin of high specific activity. PBPs in identical amounts of solubilized envelope protein were separated by SDS-PAGE. The resistant strains HR and LR and the four sensitive strains agreed in the pattern and electrophoretic mobilities of the PBPs (Fig. 2). The numbering of the PBPs relied on the observed selective binding of mecillinam to PBP 2, and of cephalexin, aztreonam and ceftazidime to PBP 3, as known from Escherichia coli and other enterobacteria (Spratt, 1977; Curtis et al., 1979; Georgopapadakou, 1988). On PAGE analysis of larger samples, an additional minor PBP 3A was consistently found (Fig. 2). However, this PBP showed no selectivity or high affinity for any $\beta$-lactam and was therefore not considered further.

Representative counts of radioactively labelled PBPs in equal quantities of envelopes from resistant and sensitive $S$. marcescens strains are given in Table 1 . Numbers of molecules of PBPs per cell were calculated from the amounts of radioactivity in known numbers of bacteria, assuming the formation of equimolar covalent complexes from $\left[{ }^{3} \mathrm{H}\right]$ benzylpenicillin and PBPs. Most of the eight PBPs were found in similar quantities in strain LR and in the four unrelated, sensitive strains. We conclude that the low resistance of $S$. marcescens strain LR is not connected with the increase of any PBP. In contrast, the highly resistant strain HR differed from the related strain $L R$ and the sensitive strains by a more than twofold higher content of PBP 6 . The augmentation of a low molecular mass PBP in highly $\beta$-lactam-resistant Pseudomonas aeruginosa (Godfrey et al., 1981), and of PBP 6 in resistant $S$. marcescens (Gutmann \& Chabbert, 1984 ) has been reported previously. It is not clear how the doubling of the amount of PBP 6, a non-essential PBP in enterobacteria, should contribute to the high $\beta$-lactam resistance of strain $\mathrm{HR}$. Also, the significance of the observed smaller increase of PBP 3 in cells of strain HR remains uncertain.

Comparison of sensitivities of PBPs for extended-spectrum $\beta$-lactams in $S$. marcescens strains $H R$ and $L R$

Sensitivities of the essential PBPs 1A, B, C, 2 and 3 in isolated cell envelopes of strains $H R$ and $L R$ were determined as concentrations $\left(\mathrm{EC}_{50}\right)$ of different extended-spectrum $\beta$-lactams preventing the binding of $\left[{ }^{3} \mathrm{H}\right]$ benzylpenicillin to $50 \%$ of the amounts of individual PBPs, as described in Methods. The results did not reveal significantly different sensitivities of PBPs in $S$. marcescens strains LR and HR (Table 2). This agrees with our previous, tentative conclusions from model calculations that target sensitivities are the same in the high and low states of resistance of $S$. marcescens strains 


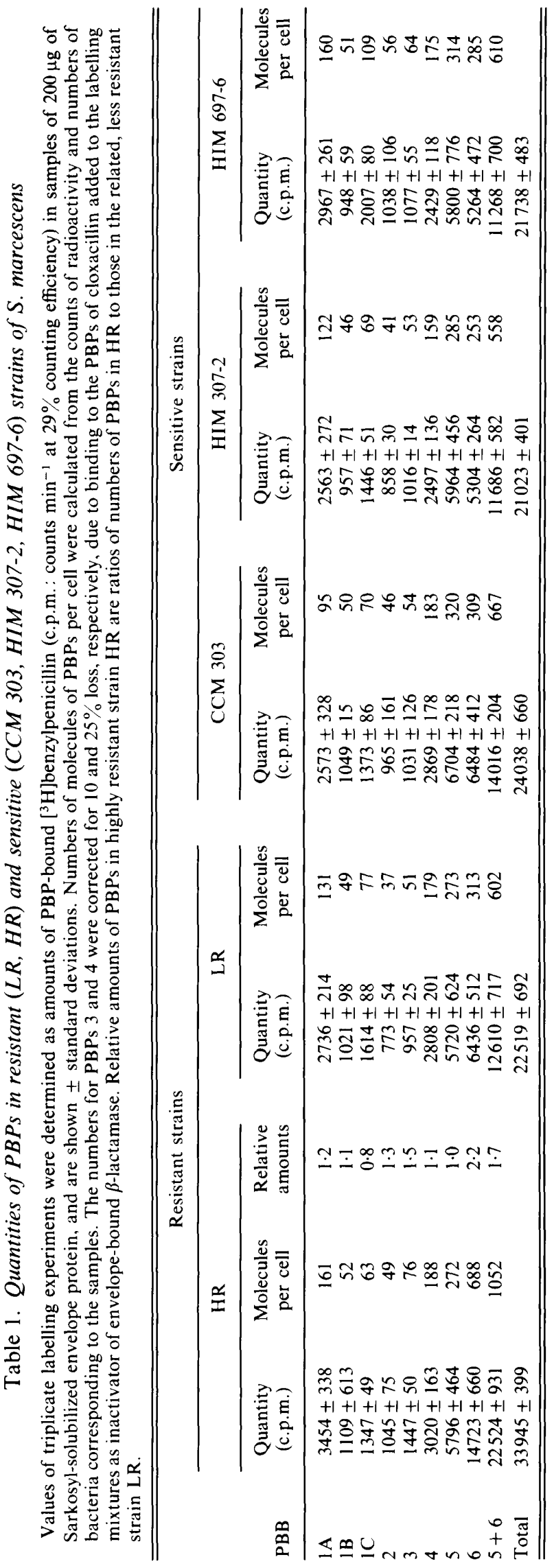


Table 2. EC 50 values of antibiotics for essential PBPs in isolated envelopes of $S$. marcesceus $L R$ and $H R$

\begin{tabular}{|c|c|c|c|c|c|c|c|c|}
\hline \multirow[b]{2}{*}{ PBP } & \multicolumn{2}{|c|}{ Cefotaxime } & \multicolumn{2}{|c|}{ Aztreonam } & \multicolumn{2}{|c|}{ Ceftazidime } & \multicolumn{2}{|c|}{ Imipenem } \\
\hline & LR & HR & LR & HR & LR & HR & LR & HR \\
\hline $1 \mathrm{~A}$ & 1 & $<1$ & 2 & 4 & 8 & 8 & $0 \cdot 25$ & $0 \cdot 25$ \\
\hline IB & 4 & 2 & $>8$ & $>8$ & 32 & 32 & $>1$ & $>1$ \\
\hline $1 \mathrm{C}$ & 4 & 4 & $>8$ & $>8$ & 32 & 32 & $>1$ & $>1$ \\
\hline 2 & 4 & 4 & $>8$ & $>8$ & $>32$ & 32 & 0.06 & 0.06 \\
\hline 3 & $<1$ & $<1$ & $\ll 0.5$ & $\ll 0.5$ & $\ll 2$ & $\ll 2$ & $<1$ & $<1$ \\
\hline
\end{tabular}

HR and LR, and are presumably also identical with those in sensitive $S$. marcescens strains (Hechler et al., 1989). Confirmation of this concept will require detailed analysis of the kinetic parameters of PBP- $\beta$-lactam interaction, as described by Frère \& Joris (1985) and by Ghuysen et al. (1986). The observation of identical target sensitivities, if confirmed, will also support our previous assumption that the required lethal periplasmic concentrations $\left(I_{p l}\right)$ (Frère, 1989) of the antibiotics are the same in sensitive and resistant $S$. marcescens (Hechler et al., 1989).

The $\mathrm{EC}_{50}$ values also showed that sensitivities of essential PBPs for the individual antibiotics differed considerably. Sensitivity to cefotaxime, ceftazidime and aztreonam was high $\left(\mathrm{EC}_{50} \ll 1 \mu \mathrm{g} \mathrm{ml}^{-1}\right)$ for only one target, PBP 3, and moderately high for PBP 1A. In contrast, sensitivity to imipenem was high for PBPs 2 and $1 \mathrm{~A}$, and also moderately high for PBP 3 . With the exception of high sensitivity of PBP 4 to imipenem $\left(\mathrm{EC}_{50}, 0.06 \mu \mathrm{g} \mathrm{ml}^{-1}\right)$, the non-essential PBPs 4, 5 and 6 had low sensitivities for the tested $\beta$-lactams (data not shown). High sensitivities of multiple PBPs to imipenem have been reported previously for non-resistant $E$. coli (Spratt et al., 1977; Georgopapadakou, 1988). We will discuss below why this exceptional feature may be a major cause of the so far unexplained low resistance of both LR and HR strains to imipenem, with MICs of 1 and $4 \mu \mathrm{g} \mathrm{ml}^{-1}$, respectively (Hechler et al., 1989).

\section{Binding of $\beta$-lactams to PBPs in growing cells of $S$. marcescens strains $H R$ and $L R$}

Typical defects in cell shape were observed microscopically in $S$. marcescens strains LR and HR growing at subinhibitory concentrations of different antibiotics in the MIC assay. The amidinopenicillin mecillinam was not growth-inhibitory for HR or LR strains even at $1024 \mu \mathrm{g} \mathrm{ml}^{-1}$. However, it caused formation of round cells at the much lower concentration of $4 \mu \mathrm{g} \mathrm{ml}^{-1}$. This was in keeping with its known specific binding to enterobacterial PBP 2 and the ensuing inhibition of the formation of rod-shaped cells. In the presence of cefotaxime, ceftazidime or aztreonam, at one-quarter and less of their MICs $\left(1024,64\right.$ and $128 \mu \mathrm{g} \mathrm{m}^{-1}$ for strain HR, and 32,1 and $8 \mu \mathrm{g} \mathrm{ml}^{-1}$ for strain LR, respectively), the bacteria grew as filaments. This indicated binding of these antibiotics to PBP 3 and inactivation of its specific function for cell division (Spratt, 1975). Therefore, the interaction of $\beta$-lactams with targets in intact cells of the resistant bacteria was measured. The growing bacteria were exposed to different antibiotics over a range of concentrations from $0.25 \times$ MIC for strain LR to $2 \times$ MIC for strain HR. Exposure time was $30 \mathrm{~min}$, corresponding to one generation time of LR-cells. The binding data are presented in Fig. 3.

It is obvious that the quantification of the PBP- $\beta$ lactam interaction in growing bacteria suffers from unavoidable imperfections and technical difficulties. MICs of antibiotics cannot be strictly correlated with the measured extent of their binding to PBPs in bacteria because 100 -fold higher cell densities were necessary to obtain sufficient yields of membranes for PBP assays. At this higher cell density, $\beta$-lactams will be more extensively degraded by the periplasmic $\beta$-lactamase than at the low cell densities $\left(10^{5}-10^{6}\right.$ cells $\left.\mathrm{ml}^{-1}\right)$ of the standard MIC assay. The measured binding of extended spectrum $\beta$-lactams includes only the covalent PBP- $\beta$-lactam complexes which formed sufficiently rapidly and remained stable under the chosen conditions of preincubation and post-labelling of free PBPs. Therefore, our data probably underestimate the degree of PBP inactivation at the MICs. With this in mind, we report the following observations and tentative conclusions.

1. In both LR and HR strains, binding of cefotaxime, ceftazidime, aztreonam and imipenem to PBPs took place even at concentrations of $8,0.25,2$, and $0.25 \mu \mathrm{g} \mathrm{ml}^{-1}$, respectively. These values corresponded to one-quarter of the MICs of LR, and to fractions of the 

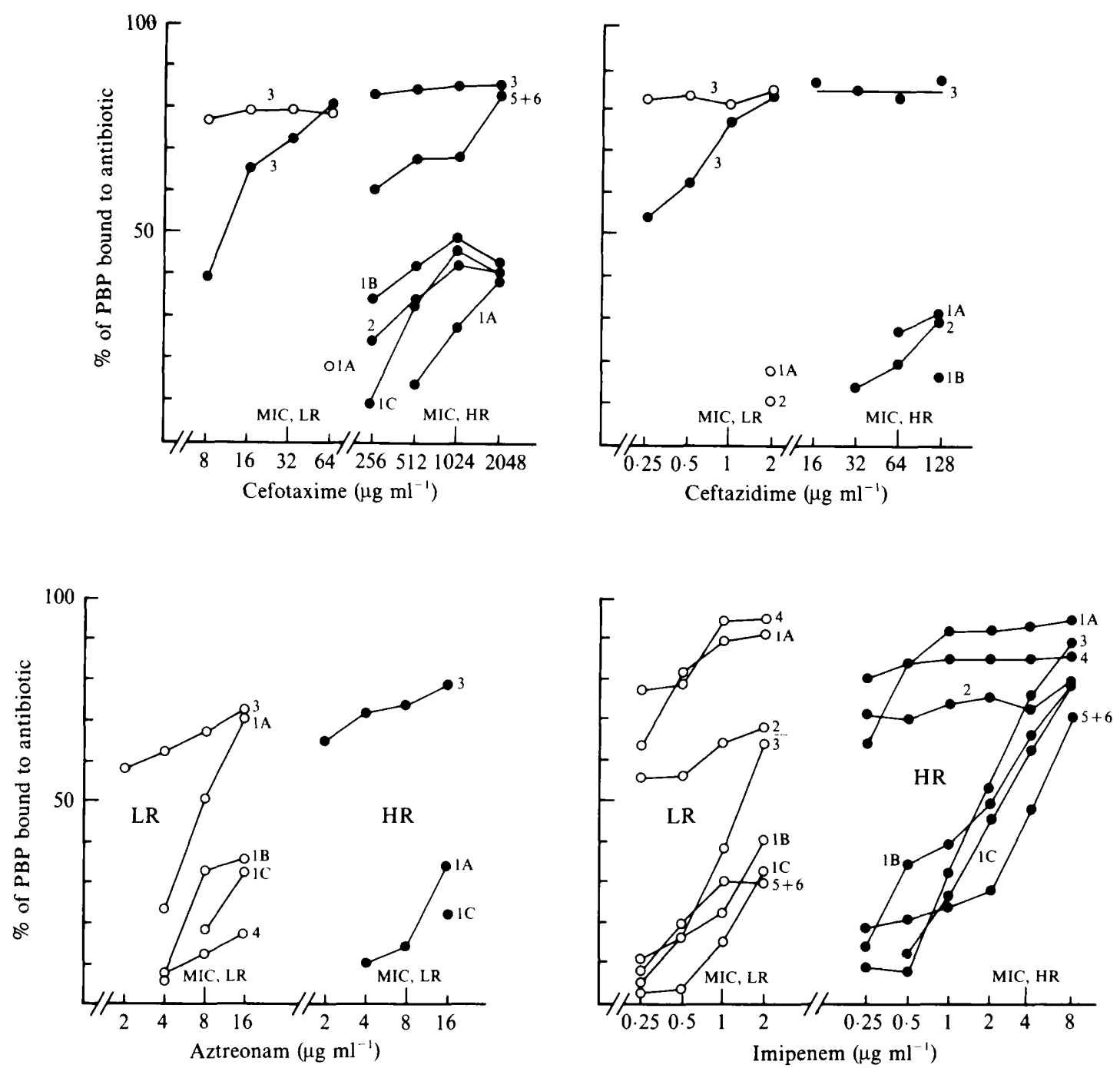

Fig. 3. Binding of different extended-spectrum $\beta$-lactam antibiotics to PBPs in growing cells of $S$. marcescens LR $(O)$ and $H R(\Theta)$. The bacteria were incubated with $\beta$-lactams for $30 \mathrm{~min}$, i.e. one generation time of strain LR. Concentrations of antibiotics were from $0.25 \times$ MIC for strain LR to $2 \times$ MIC for strain HR. Subsequently, envelopes were isolated and those fractions of PBPs which had not bound $\beta$-lactams in whole cells were labelled with $\left[{ }^{3} \mathrm{H}\right]$ benzylpenicillin.

MICs for $\mathrm{HR}$ ranging from $1 / 32$ to $1 / 256$. The binding involved a minimum of $40 \%$, and in most cases much more, of at least one of the PBPs thought to be essential in enterobacteria. Thus, even far below their MICs, $\beta$ lactams were not excluded from their targets by the outer-membrane- $\beta$-lactamase barrier of resistant $S$. marcescens.

2. In HR cells; cefotaxime, ceftazidime and aztreonam at subinhibitory concentrations up to 64,16 and $2 \mu \mathrm{g} \mathrm{ml}^{-1}$, respectively, bound only to PBP 3 , the single target with high sensitivity $\left(\mathrm{EC}_{50} \leqslant 1 \mu \mathrm{g} \mathrm{ml}^{-1}\right)$ to these antibiotics. Under these conditions, $60-80 \%$ of this PBP was bound. However, this extensive inactivation of a single essential PBP was obviously not lethal for resistant $S$. marcescens.
Binding of mecillinam to PBPs in growing HR cells was measured at 2,4 and $8 \mu \mathrm{g} \mathrm{ml}^{-1}$. These values represent $0 \cdot 5,1$ and 2 times the minimal concentration of the antibiotic for uniform formation of round cells. Binding took place to PBP 2 only, to the extent of 12,25 and $31 \%$, respectively.

3. Maximal binding of cefotaxime and ceftazidime to PBP 3 in strain HR required eight-fold higher concentrations of the antibiotics than in strain LR. At 64 and $2 \mu \mathrm{g} \mathrm{ml}^{-1}$, respectively, these concentrations were still well below the MICs for strain HR. This requirement may be due to a lower outer membrane permeability of HR cells, as previously determined with the mathematical models (Hechler et al., 1989). A defective permeability barrier in HR cells was also suggested by 
our recent observation that outer membranes of strain HR are distinguished from those of strain LR by the reduced content of a $42 \mathrm{kDa}$ protein. This protein resembled the OmpF porin of $E$. coli (Lugtenberg \& Van Alphen, 1983) in peptidoglycan association and osmoregulation of expression $(\mathrm{H}$. Weindorf \& $\mathrm{H}$. H. Martin, unpublished data).

4. At and above their MICs, cefotaxime, ceftazidime and aztreonam bound to additional, less sensitive targets, predominantly to PBP $1 \mathrm{~A}$, in addition to extensive binding to PBP 3 . Thus, inactivation of multiple essential PBPs, specifically PBPs 3 and 1A, may be necessary to kill the bacteria. The same conclusion was reached previously for non-resistant $E$. coli and Salmonella typhimurium (Chase et al., 1981). The $\mathrm{I}_{\mathrm{pl}}$ and respective MIC should then be those concentrations of a $\beta$-lactam which inactivate all lethal targets, including the least sensitive essential PBP. By rigorous quantitative analysis, the high MICs of some extended-spectrum $\beta$ lactams in resistant Gram-negative bacteria have been explained as those externally applied concentrations which still allow the antibiotics to reach the $I_{p}$, in spite of their extensive degradation during their passage through the outer membrane- $\beta$-lactamase barrier (Nikaido \& Normark, 1987; Frère, 1989; Hechler et al., 1989). Kinetic binding parameters of the essential multiple targets to individual $\beta$-lactams, once established, should contribute further to these resistance models.

5. Imipenem differed from the other antibiotics by binding to multiple targets in whole cells at concentrations below the MIC. At $0.25 \mu \mathrm{g} \mathrm{ml}^{-1}$, i.e. $1 / 4$ and $1 / 32$ of the MICs for strains LR and HR ( 1 and $4 \mu \mathrm{g} \mathrm{ml}^{-1}$, respectively), imipenem bound to more than $50 \%$ of PBPs 2, 4 and 1A. With increasing concentration up to the MICs, significant binding to all other PBPs $(3,1 \mathrm{~B}$, $1 \mathrm{C}, 5$ and 6) took place.

An exceptional ability of imipenem to remain growthinhibitory at low concentration has been reported frequently for $\beta$-lactamase-overproducing and penetration-restricted Enterobacter cloacae highly resistant to other extended-spectrum $\beta$-lactams (Bush et al., 1985; Werner et al., 1985; Then \& Angehrn, 1986; Marchou et al., 1987). For $P$. aeruginosa it has been proposed that imipenem uses specific penetration channels which are impermeable for other $\beta$-lactams (Büscher et al., 1987; Nikaido, 1989). Such evidence is not yet available for enterobacteria.

Our present data suggest the alternative explanation that the high sensitivity to imipenem of several essential PBPs, especially of PBP 2, $1 \mathrm{~A}$ and 3 at $\mathrm{EC}_{50} \leqslant$ $1 \mu \mathrm{g} \mathrm{ml}^{-1}$, enables this antibiotic to simultaneously inactivate these lethal targets in growing bacteria at relatively low concentration. This antibiotic may thus be able to kill bacteria at a low $\mathrm{I}_{\mathrm{pl}}$ and MIC in spite of its
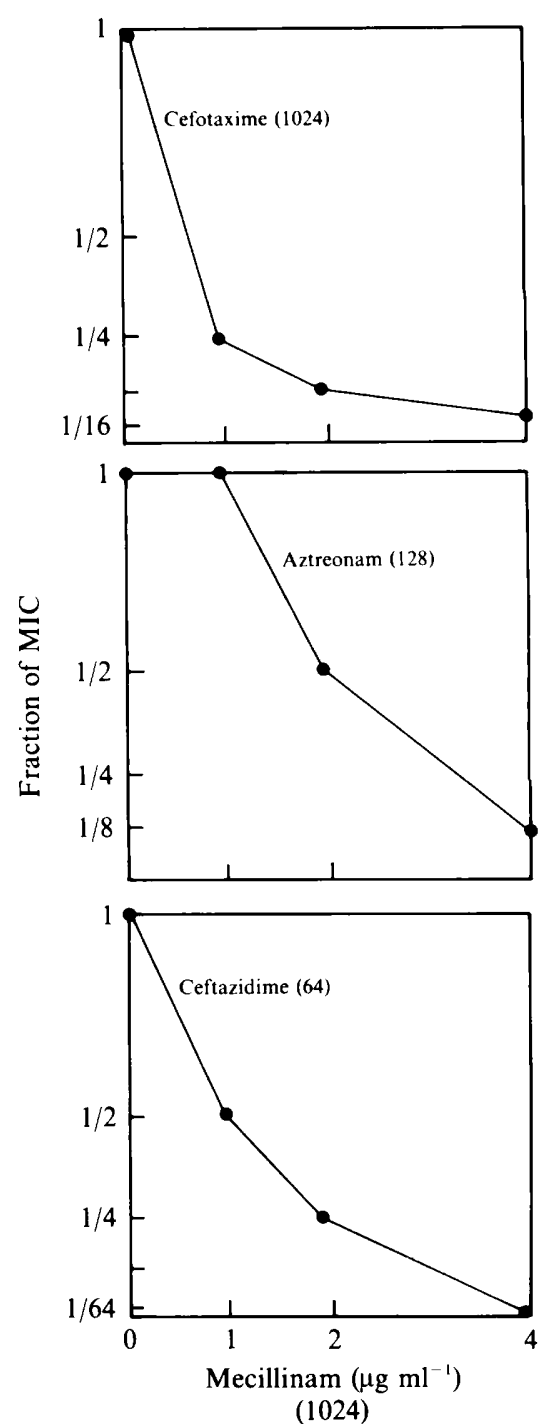

Fig. 4. Synergistic growth inhibition of highly resistant $S$. marcescens HR by combinations of different extended-spectrum $\beta$-lactams with mecillinam. The points indicate the growth-inhibitory concentrations of the respective mixtures of antibiotics. Individual MICs of the antibiotics in $\mu \mathrm{g} \mathrm{ml}^{-1}$ are given in parentheses.

appreciable degradation by the highly concentrated periplasmic concentrations of $\beta$-lactamase in resistant $S$. marcescens (Hechler et al., 1989). The moderate elevation of the MIC of imipenem to $4 \mu \mathrm{g} \mathrm{ml}^{-1}$ in strain HR could then be caused by the decreased permeability of $\mathrm{HR}$ cells.

Bactericidal synergism of $\beta$-lactam antibiotics by multiple target inactivation in the highly resistant $S$. marcescens strain $H R$

If bactericidal action depends on the inactivation of more than one essential PBP, synergistic killing of the bacteria could be expected from combinations of $\beta$ - 


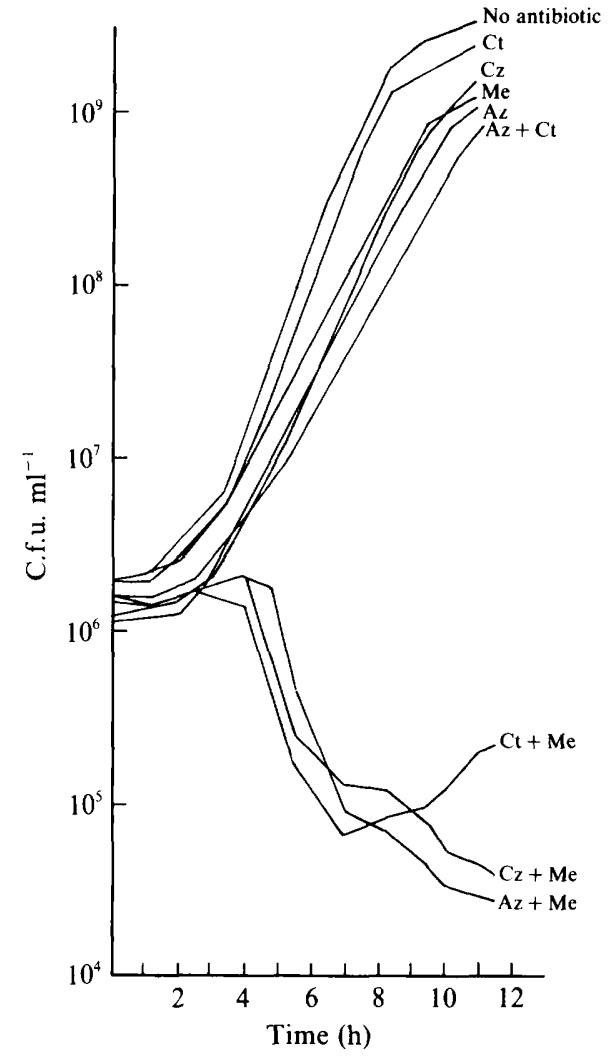

Fig. 5. Bactericidal kinetics of combinations of extended-spectrum $\beta$ lactams with mecillinam in highly resistant $S$. marcescens $H R$. The following concentrations of antibiotics $\left(\mu \mathrm{g} \mathrm{ml}^{-1}\right)$ were present individually or in combinations at the time of inoculation of the cultures: mecillinam (Me) 4, cefotaxime (Ct) 64, ceftazidime (Cf) 2, aztreonam (Az) 16. Absence of bactericidal synergism by inactivation of the bacterial $\beta$-lactamase was demonstrated by the growth curve with the combination of cefotaxime with $\beta$-lactamase-inactivating aztreonam.

lactams with different binding selectivities. At concentrations below their individual MICs, these should achieve simultaneous binding to two or more essential PBPs having high sensitivity to the respective antibiotics. Combinations of the PBP-2-binding mecillinam with different PBP-3-binding antibiotics were therefore tested.

Alternatively, support of the growth inhibitory action of one $\beta$-lactam could result from the function of a second $\beta$-lactam as inactivator of the periplasmic $\beta$-lactamase of the bacteria. This was tested by combinations with aztreonam. As shown previously (Hechler et al., 1989), aztreonam is a highly effective inactivator of chromosomally encoded $\beta$-lactamase of $S$. marcescens because of its very high affinity for the enzyme $\left(K_{\mathrm{m}} 0.012 \mu \mathrm{M}\right)$, the rapid formation of enzymically inactive acyl-enzyme $\left(k_{2} / K 1.6 \times 10^{4} \mathrm{M}^{-1} \mathrm{~s}^{-1}\right)$, and the effective immobilization as acyl-enzyme with a very low decay rate $\left(k_{3}\right.$ $1.5 \times 10^{-4} \mathrm{~s}^{-1}$ ).
Results of checkerboard assays of antibiotic combinations (Fig. 4) and of bactericidal kinetics (Fig. 5) supported the first alternative. For strain HR, MIC values of cefotaxime, aztreonam and ceftazidime were reduced from 1024 to 64 , from 128 to 16 , and from 64 to $1 \mu \mathrm{g} \mathrm{ml}^{-1}$, respectively, in the presence of $4 \mu \mathrm{g}$ mecillinam $\mathrm{ml}^{-1}$. In contrast, the MIC of cefotaxime remained unchanged at $1024 \mu \mathrm{g} \mathrm{ml}^{-1}$ when aztreonam was added up to $32 \mu \mathrm{g} \mathrm{ml}^{-1}$, i.e. $1 / 4$ of the MIC of this antibiotic (Fig. 4).

Experiments on bactericidal kinetics of the same antibiotic combinations with strain HR were carried out as described in Methods. As shown in Fig. 5, combinations of mecillinam $\left(4 \mu \mathrm{g} \mathrm{ml}^{-1}\right)$ with cefotaxime, aztreonam or ceftazidime, at 64,16 and $2 \mu \mathrm{g} \mathrm{ml}^{-1}$, respectively, were bactericidal. On the other hand, the combination of cefotaxime with 16 or $32 \mu \mathrm{g} \mathrm{ml}^{-1}$ aztreonam was not bactericidal, and retarded the growth of HR cells only slightly more than the single antibiotics. Synergism of mecillinam with other $\beta$-lactams has been reported frequently in enterobacteria (Tybring \& Melchior, 1975; Baltimore et al., 1976; Neu, 1976; Gutmann et al., 1986). In the highly $\beta$-lactamase-overproducing $S$. marcescens strain HR it was the more remarkable since Serratia $\beta$-lactamase hydrolysed mecillinam much more effectively than the extended-spectrum $\beta$-lactams. The enzyme was also not inactivated by mecillinam (M. Van den Weghe, unpublished results).

We are grateful to Dr Kathryn Nixdorff for critical review of the manuscript. We thank $\mathrm{H}$. Weindorf for carrying out some of the experiments on bactericidal kinetics. This work was supported by grants from the Deutsche Forschungsgemeinschaft and the Fonds der Chemischen Industrie.

\section{References}

Baltimore, R. S., Klein, J. O., Wilcox, C. \& Finland, M. (1976). Synergy of mecillinam (FL1060) with penicillins and cephalosporins against Proteus and Klebsiella, with observations on combinations with other antibiotics and against other bacterial species. Antimicrobial Agents and Chemotherapy 9, 701-705.

Büscher, K. H., CullmanN, W., Dick, W. \& Opferkuch, W. (1987). Imipenem resistance in Pseudomonas aeruginosa resulting from diminished expression of an outer membrane protein. Antimicrobial Agents and Chemotherapy 31, 703-708.

Bush, K., Tanaka, S. K., Bonner, D. P. \& Sykes, R. B. (1985). Resistance caused by decreased penetration of $\beta$-lactam antibiotics into Enterobacter cloacae. Antimicrobial Agents and Chemotherapy 27, $555-560$.

Chase, H. A., Fuller, C. \& Reynolds, P. E. (1981). The role of penicillin-binding proteins in the action of cephalosporins against Escherichia coli and Salmonella typhimurium. European Journal of Biochemistry 117, 301-310.

Curtis, N. A. C., Orr, D., Ross, G. W. \& Boulton, M. G. (1979). Competition of $\beta$-lactam antibiotics for the penicillin-binding proteins of Pseudomonas aeruginosa, Enterobacter cloacae, Klebsiella aerogenes, Proteus rettgeri, and Escherichia coli: comparison with antibacterial activity and effects upon bacterial morphology. Antimicrobial Agents and Chemotherapy 16, 325-328. 
De Meester, F., Frère, J. M., Waley, S. G., Cartwright, S. G., VIRDEN, R. \& LINDBERG, F. (1986). 6- $\beta$-Iodopenicillinate as a probe for the classification of $\beta$-lactamases. Biochemical Journal 239, 575-580.

FRÈRE, J. M. (1989). Quantitative relationship between sensitivity to $\beta$ lactam antibiotics and $\beta$-lactamase production in Gram-negative bacteria - I. Steady state treatment. Biochemical Pharmacology 38 $1415-1426$.

Frère, J. M. \& JoRIS, B. (1985). Penicillin-sensitive enzymes in peptidoglycan synthesis. CRC Critical Reviews in Microbiology 11, 299-396.

Frère, J. M., Joris, B., Crine, M. \& Martin, H. H. (1989). Quantitative relationship between sensitivity to $\beta$-lactam antibiotics and $\beta$-lactamase production in Gram-negative bacteria. II. Nonsteady-state treatment and progress curves. Biochemical Pharmacology 38, 1427-1433.

Georgopapadakou, N. H. (1988). Penicillin-binding proteins. In Antimicrobial Agents Annual 3, pp. 409-431. Edited by P. K. Peterson \& J. Verhoef. Amsterdam: Elsevier Science Publishers.

Ghuysen, J. M., Frère, J. M., Leyh-Bouille, M., NGUYeNDistÈCHE, M. \& CoYeTTE, J. (1986). Active-site-serine D-alanyl-Dalanine-cleaving-peptidases-catalysed acyl-transfer reactions. Procedures for studying the penicillin-binding proteins of bacterial plasma membranes. Biochemical Journal 235, 159-165.

Godfrey, A. J., Bryan, L. E. \& RABIN, H. R. (1981). $\beta$-Lactamresistant Pseudomonas aeruginosa with modified penicillin-binding proteins emerging during cystic fibrosis treatment. Antimicrobial Agents and Chemotherapy 19, 705-711.

Gutmann, L. \& ChabberT, Y. A. (1984). Different mechanisms of resistance to latamoxef (moxalactam) in Serratia marcescens. Journal of Antimicrobial Chemotherapy 13, 15-22.

Gutmann, L., Vincent, S. Billot-Klein, D., Acar, J. F., Mrèna, E. \& Williamson, R. (1986). Involvment of penicillin-binding protein 2 with other penicillin-binding proteins in lysis of Escherichia coli by some $\beta$-lactam antibiotics alone and in synergistic lytic effect of amdinocillin (mecillinam). Antimicrobial Agents and Chemotherapy 30, 906-912.

Hechler, U., Van den Weghe, M., Martin, H. H. \& Frère, J. M. (1989). Overproduced $\beta$-lactamase and the outer membrane barrier as resistance factors in Serratia marcescens highly resistant to $\beta$ lactamase-stable $\beta$-lactam antibiotics. Journal of General Microbiology 135, 1275-1290.

JACK, G. W. \& RICHMOND, M. H. (1970). A comparative study of eight different $\beta$-lactamases synthesized by Gram-negative bacteria. Journal of General Microbiology 61, 43-61.

Krogstad, D. J. \& Moellering, R. C., JR (1980). Combinations of antibiotics, mechanisms of interaction against bacteria. In Anti- biotics in Laboratory Medicine, pp. 298-341. Edited by V. Lorian. Baltimore \& London: Williams \& Wilkins.

LUGTENBERG, B. \& VAN AlPHEN, L. (1983). Molecular architecture and functioning of the outer membrane of Escherichia coli and other Gram-negative bacteria. Biochimica et Biophysica Acta 737, 51-115.

Marchou, B., Bellido, F., Charnas, R., Lucain, C. \& Pechère, J. C. (1987). Contribution of $\beta$-lactamase hydrolysis and outer membrane permeability to ceftriaxone resistance in Enterobacter cloacae. Antimicrobial Agents and Chemotherapy 31, 1589-1595.

Miller, J. H. (1972). Experiments in Molecular Genetics. Cold Spring Harbor, NY: Cold Spring Harbor Laboratory.

NeU, H. C. (1976). Synergy of mecillinam, a beta-amidinopenicillanic acid derivative, combined with beta-lactam antibiotics. Antimicrobial Agents and Chemotherapy 10, 535-542.

NikAido, H. (1989). Outer membrane barrier as mechanism of antimicrobial resistance. Antimicrobial Agents and Chemotherapy 33, 1831-1836.

Nikaido, H. \& Normark, S. (1987). Sensitivity of Escherichia coli to various $\beta$-lactams is determined by the interplay of outer membrane permeability and degradation by periplasmic $\beta$-lactamases: a quantitative predictive treatment. Molecular Microbiology 1, 29-36.

SPRATT, B. G. (1975). Distinct penicillin-binding proteins involved in the division, elongation, and shape of Escherichia coli K12. Proceedings of the National Academy of Sciences of the United States of America 72, 2999-3003.

SPRaTT, B. G. (1977). Properties of the penicillin-binding proteins of Escherichia coli K12. European Journal of Biochemistry 72, 341-352.

SPRatT, B. G., JobanPuTRa, V. \& ZimmermanN, W. (1977). Binding of thienamycin and clavulanic acid to the penicillin-binding proteins of Escherichia coli K12. Antimicrobial Agents and Chemotherapy 12, 406-409.

Then, R. L. \& ANGeHRN, P. (1986). Multiply resistant mutants of Enterobacter cloacae selected by $\beta$-lactam antibiotics. Antimicrobial Agents and Chemotherapy 30, 684-688.

TYBRING, L. \& MeLCHIOR, N. H. (1975). Mecillinam (FLI060), a 6- $\beta$ amidinopenicillanic acid derivative : bactericidal action and synergy in vitro. Antimicrobial Agents and Chemotherapy 8, 271-276.

Vu, H. \& Nixaido, H. (1985). Role of $\beta$-lactam hydrolysis in the mechanism of resistance of a $\beta$-lactamase-constitutive Enterobacter cloacae strain to expanded-spectrum $\beta$-lactams. Antimicrobial Agents and Chemotherapy 27, 393-398.

Werner, V., Sanders, C. C., SANders, W. E. Jr, \& Goering, R. V. (1985). Role of $\beta$-lactamases and outer membrane proteins in multiple $\beta$-lactam resistance of Entgerobacter cloacae. Antimicrobial Agents and Chemotherapy 27, 455-459. 